WellBeing International

WBI Studies Repository

2008

\title{
Processing of the Müller-Lyer Illusion by a Grey Parrot (Psittacus erithacus)
}

Irene M. Pepperberg

Harvard University

Jennifer Vicinay

Brandeis University

Patrick Cavanagh

Harvard University

Follow this and additional works at: https://www.wellbeingintlstudiesrepository.org/acwp_asie

Part of the Animal Studies Commons, Comparative Psychology Commons, and the Other Animal

Sciences Commons

\section{Recommended Citation}

Pepperberg, I. M., Vicinay, J., \& Cavanagh, P. (2008). Processing of the Müller-Lyer illusion by a grey parrot (Psittacus erithacus). Perception, 37(5), 765-781.

This material is brought to you for free and open access by WellBeing International. It has been accepted for inclusion by an authorized administrator of the WBI Studies Repository. For more information, please contact wbisr-info@wellbeingintl.org.

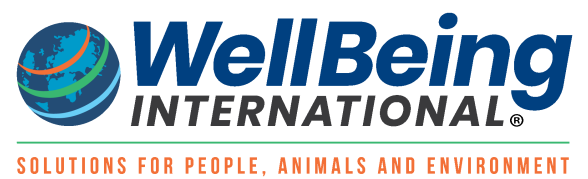




\title{
Processing of the Müller-Lyer illusion by a Grey Parrot (Psittacus erithacus)
}

\author{
Irene M. Pepperberg ${ }^{1,2}$, Jennifer Vicinay ${ }^{2}$, Patrick Cavanagh $^{1}$ \\ ${ }^{1}$ Harvard University \\ ${ }^{2}$ Brandeis University
}

\begin{abstract}
Alex, a Grey parrot (Psittacus erithacus) who identifies the bigger or smaller of two objects by reporting its color or matter using a vocal English label and who states "none" if they do not differ in size, was presented with two-dimensional Müller-Lyer figures (Brentano form) in which the central lines were of contrasting colors. His responses to "What color bigger/smaller?" demonstrated that he saw the standard length illusion in the Müller-Lyer figures in 32 of 50 tests where human observers would also see the illusion and reported the reverse direction only twice. He did not report the illusion when (a) arrows on the shafts were perpendicular to the shafts or closely approached perpendicularity, (b) shafts were 6 times thicker than the arrows, or (c) after being tested with multiple exposures--conditions that also lessen or eliminate the illusion for human observers. These data suggest that parrot and human visual systems process the Müller-Lyer figure in analogous ways despite a 175-fold difference in the respective sizes of their brain volumes. The similarity in results also indicates that parrots with vocal abilities like Alex's can be reliably tested on visual illusions with paradigms similar to those used on human subjects.
\end{abstract}

\section{Introduction}

Given that the goal of the visual system is to process information accurately--as a matter of survival--the ability of the human brain to be fooled by optical illusions attracts considerable empirical and theoretical interest. The study of optical illusions in birds, small prey-animals with the capacity for flight and thus likely an even greater need for visual accuracy, would provide important insights into the processing strategies of the avian visual system. Some perceptual tasks, such as occlusion on non-optical-illusion visual object recognition, recognition-by-component (eg DiPietro et al 2002; van Hamme et al 1992; also Cook 2001) or detecting patterns of non-random perceptual structure (eg Cook et al 2005) have been examined in birds, but only a few conclusive studies on optical illusions have been performed on subjects with a visual system markedly different from those of primates (eg Fujita et al 1993; Nakamura et al 2006). How might non-mammalian brains process such information?

The avian brain is anatomically distinct from that of mammals but, at least for birds such as corvids and psittacids, differs quantitatively rather than qualitatively from mammals when processing certain cognitive tasks (eg Emery and Clayton 2004; Jarvis et al 2005; Pepperberg 1999, 2006); for tasks that primarily involve visual processing, however, differences may be more striking. Some avian systems differ considerably from those of humans in both structure and function (eg the double fovea of raptors--see 
Frost et al 1990). In humans, object recognition is associated with ventral streams of the extrastriate visual areas; object position and motion are associated with dorsal streams; and, overall, the lemnothalamic pathway is highly developed with respect to vision. For pigeons, in contrast, the collothalamic pathway is the more highly developed with respect to vision and the correspondence to the mammalian ventral/dorsal streams appears to be caudal/rostral streams involving the nucleus Rotundus and the ecostriatum (see Nguyen et al 2004). Pigeons' visual system, including right-eye dominance for visual discrimination learning, may explain why they favor "a featural strategy in analysis of visual scenes" and may fail to respond to some optical illusions (see discussion in Regolin et al 2004, page 163). More like humans are chickens, which use the lemnothalamic visual system for tasks that rely on frontal viewing, and show "a more balanced and complementary use of the two-eye system", which may assist in their more global systems of visual analysis (again, see Regolin et al 2004, page 163). Early papers suggested that chickens (Winslow 1933), ring doves (Warden and Baar 1929), pigeons (Fujita et al 1993; Nakamura et al 2006), and both starlings and finches (Dücker 1966) perceived various optical illusions; some of these studies, however, involved training birds to distinguish a particular stimulus and then recognize the pattern in testing.

No illusion experiments have been performed on parrots, larger-brained and longer-lived birds whose visual systems have not, with the exception of studies on UV sensitivity (eg Bowmaker et al 1994, 1996; Cuthill et al 2000; Goldsmith and Butler 2005; Wilkie et al 1998), been examined as extensively as that of pigeons or chickens. Behavioral similarities between chickens and parrots, and differences between parrots and pigeons, on tasks such as object permanence that require amodal completion (see review in Regolin et al 2004; note Aust and Huber 2006) merely suggest that parrot visual systems more closely resemble those of chickens than pigeons ${ }^{1}$. Furthermore, no studies have been performed on an avian subject that, without any training on the actual task, could simply state vocally whether or not an optical illusion had been observed. Determining whether a parrot could respond in such a manner would provide comparative behavioral data and a basis for future comparative studies on more complex types of visual processing; such data might also stimulate neurobiological studies on parrot visual systems.

The Müller-Lyer illusion was chosen as the initial task because it is well-represented in the scientific literature. Müller-Lyer (1889/1981) first described how humans either underestimated or overestimated the length of a line that had arrows attached, respectively, either inwardly $<>$ or outwardly $><$. Researchers suggest that the illusion can result from "... several factors interacting at different levels of visual processing, ranging from low-level mechanisms such as optical blur and retinal inhibition, to highlevel mechanisms, such as cognitive contrast and visual attention" (Predebon 2004, page 916); Sekuler and Erlebacher (1971) argue that the arrows-in and arrows-out Müller-Lyer illusions are functionally distinct. A human with visual agnosia failed to detect the illusion, suggesting that it depends on pictorialdepth cues (Gregory 1968; Turnbull et al 2004), but the illusion is preserved in patients with visuospatial neglect (eg Vallar et al 2000). Changizi and Widders (2002) claim that the illusion is based on a prediction of where an observer would be moving in space [ie also a three-dimensional (3-D) cue], but other data (eg experiments and review in Zanker and Abdullah 2004) suggest that filtering in the early visual system leads to confusion about the location of line endings. Weidner and Fink (2007) argue that the Müller-Lyer illusion depends on integrating bottom - up visual and top - down cognitive processes. How would a Grey parrot, with a non-primate brain and visual system, respond to this illusion? As noted earlier, some evidence exists for the illusion in ring doves (Warden and Baar 1929), pigeons (Nakamura et al 2005, 2006), and chickens (Winslow 1933) ${ }^{2}$; these studies suggest that, whatever neurobiological systems are involved, mammalian vision may not be critical for seeing the illusion (Otto-deHaart et al 1999).

The subject in this study was Alex, a Grey parrot with previous training on relative size judgments for 3-D objects (Pepperberg and Brezinsky 1991). Using a vocal color or material label, he could identify the 
larger or smaller object within a set, or state "none" if they did not differ in size. Before being tested on Müller-Lyer figures, he was given familiarization trials to enable transfer of his relative size judgments to two-dimensional (2-D) figures. Once he began to respond appropriately, he was given various versions of the Müller-Lyer figure (see below).

The experiments were designed to answer the following queries: Does a Grey parrot (a) see the MüllerLyer illusion at all?; (b) see the illusion under varying conditions of angle and size contrast between the central line and the arrows (eg Gardner and Long 1961; note Predebon 2004)?; (c) respond appropriately under control conditions when arrows are replaced by vertical bars? and (d) habituate over time as do some humans (eg Mountjoy 1958)?

\section{Experiment}

\subsection{Subject}

Alex, a 30-year-old male Grey parrot (Psittacus erithacus, figure 1), had been the subject of numerous cognitive and communicative studies for 29 years (eg Pepperberg 1999). Testing locations and living conditions when neither testing nor training were in progress are described in Pepperberg and Wilkes (2004). Food and water were available at his vocal request at all times. In this study he used previously documented abilities [Pepperberg (1999), colors (rose \{red\}, green, purple, blue, yellow, orange, grey)], and to understand the concept of relative size and absence of size difference (Pepperberg and Brezinsky 1991).

\subsection{Procedure}

2.2.1 Familiarization. Because Alex's prior training on size difference had involved 3-D objects (Pepperberg and Brezinsky 1991) and his ability to label 2-D representations of 3-D objects was still under study, he was first shown sets of two differently colored 2-D horizontal lines and asked to identify the bigger or smaller one or to state "none" if they were equally sized. The two horizontal lines, without arrows, $4 \mathrm{~mm}$ in width and of differing colors and lengths (varying between 5 and $15 \mathrm{~cm}$ ), were drawn 5 $\mathrm{cm}$ apart on a standard white $3 \times 5$ index card; each card had different colored pairs and different size variations, including lines of equal size.

A randomly chosen card was placed on a felt-covered tray used for other tasks (eg number studies, object permanence--Pepperberg 1999, 2006). Initially, the tray was held horizontally, approximately 20 $\mathrm{cm}$ from one of Alex's eyes, with the experimenter compensating as much as possible for Alex's head movement so as to maintain presentation in front of a single eye. Subsequently, the tray was held vertically, approximately $15 \mathrm{~cm}$ from one of his eyes, to increase his attentiveness. The experimenter again compensated, as much as possible, for Alex's head movements to maintain presentation in front of one eye. Because no one has determined the extent of binocular overlap in a Grey parrot (either the angular overlap or, given the fairly large thick beak, the distance at which binocular overlap begins) nor the acuity of vision in the area of binocular overlap ${ }^{3}$, we opted to constrain presentation to what was likely to be monocular observation. (Note: Alex will not tolerate even a stray feather near his eye; thus using an eye patch to ensure monocular vision is not an option.) The distances of the stimuli from Alex's eye in this study were roughly the same as in all previous projects (eg Pepperberg 1999, 2006).

When Alex made contact with the questioner with the other eye, he was asked "What color bigger/smaller?" He could respond with either color or "none". He received one or two familiarization sessions ( $20 \mathrm{~min} / \mathrm{session}$ ) each week for about 6 months with breaks for trainer vacations; sessions continued until he attended to the cards consistently. Such training was necessary to direct his focus to the 2-D stimuli; his initial responses were to label the cards themselves (correctly) as 'paper' or 'four- 
corner paper', attempt to chew them, or, most commonly, to ignore the trainer and cards and either state colors that were not on the cards or begin to preen. We were not concerned with his accuracy because he had previously demonstrated his understanding of bigger/smaller (Pepperberg and Brezinsky 1991) and the familiarization procedure was carried out only to ensure that he would respond to the 2-D stimuli. We specifically did not wish to train him on the task by rewarding and thus reinforcing particular responses to these queries, so as to avoid cuing him about tests to follow.

Figure 1. Alex viewing one of the stimuli. During trials, the stimulus was centered on Alex's eye; for this figure, the stimulus was positioned so that it would be visible to the reader.

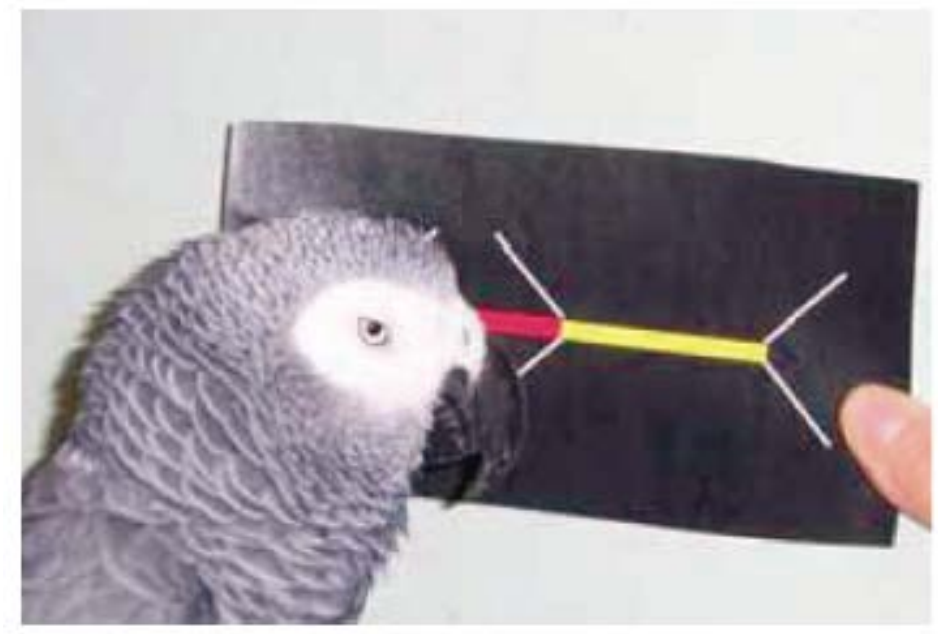

Figure 2. Colored numerals presented to Alex as a test of acuity. The numerals were presented at three different sizes $(6.3,12.7$, and $25.4 \mathrm{~mm}$ ) at approximately 10 to $15 \mathrm{~cm}$ viewing distance (same distance used for the illusion figures).

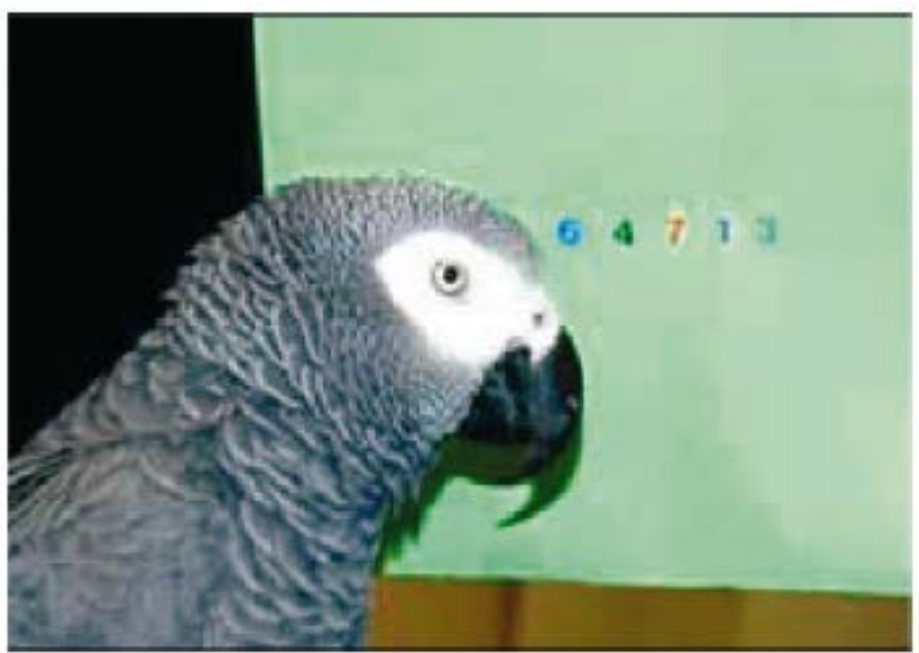

To ensure that Alex was able to focus clearly on the laterally presented stimuli, we gave him a brief test of visual acuity (figure 2). We asked him to identify the colors of variously sized numerals presented primarily to one eye (see above) at the same viewing distances that would be used for the Müller-Lyer figures. The digits 1 through 7 that Alex can identify were presented six at a time in a horizontal row with 
a space approximately twice the digit width between each. The digits were uniquely colored with one of the seven colors that Alex can name. Two different random arrangements of digits, colors, and order were constructed at each digit size, all on a light-green background. The experimenter asked "What color 7?", for example, and "orange" would be the correct answer for the display in figure 2 . The different-sized digit sets and the alternate displays for each size were selected in random order from trial to trial.

Figure 3. Representative versions of the Müller-Lyer illusion; different colors pairs represent the variety used in each figure: (a) $4 \mathrm{~mm}$ shafts and $1 \mathrm{~mm}$ arrows on a white background; (b) $4 \mathrm{~mm}$ shafts and $1 \mathrm{~mm}$ arrows on a black background; (c) $4 \mathrm{~mm}$ shafts and $1 \mathrm{~mm}$ perpendicular arrows on a black background; (d) $6 \mathrm{~mm}$ shafts and $1 \mathrm{~mm}$ arrows on a black background; (e) $2 \mathrm{~mm}$ shafts and $1 \mathrm{~mm}$ arrows on a black background; (f) $4 \mathrm{~mm}$ shafts and $4 \mathrm{~mm}$ arrows on a black background; (g) $2 \mathrm{~mm}$ shafts and $1 \mathrm{~mm}$ arrows at $80^{\circ}$; (h) $6 \mathrm{~mm}$ shafts and $1 \mathrm{~mm}$ arrows at $10^{\circ}$.

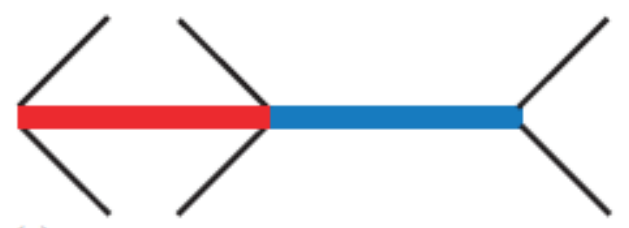

(a)

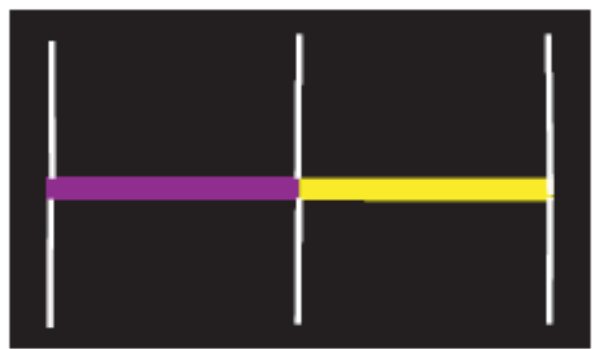

(c)

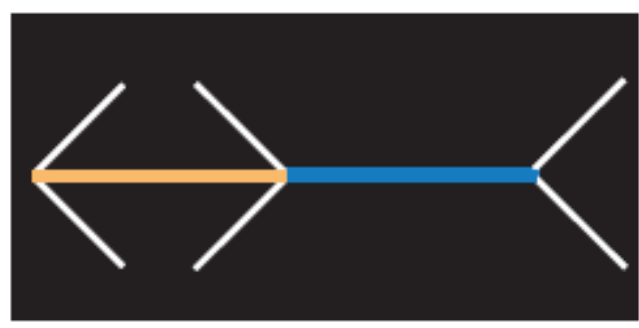

(e)

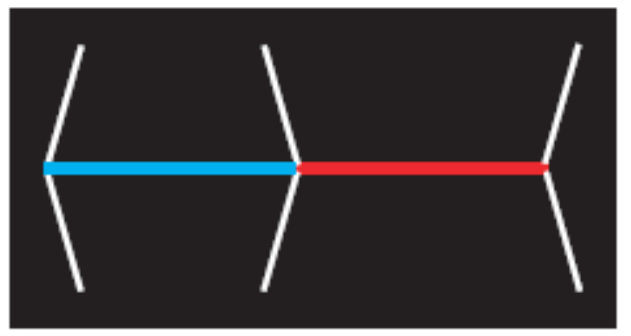

(g)

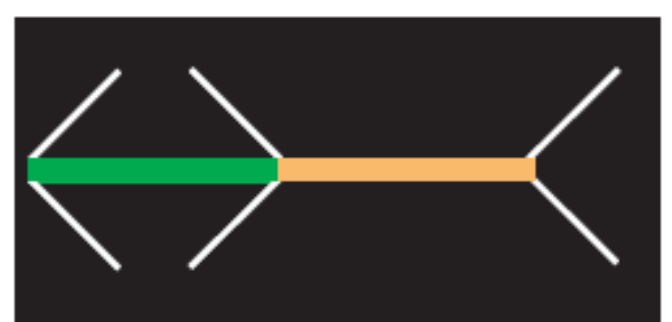

(b)

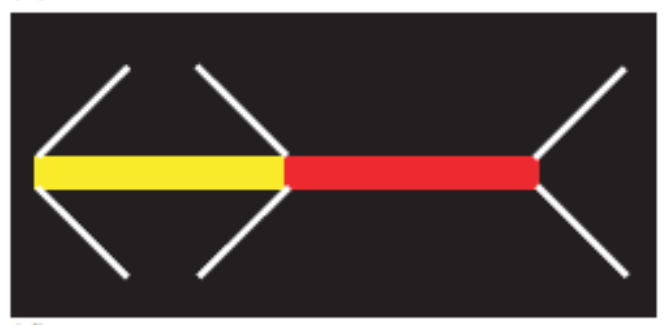

(d)

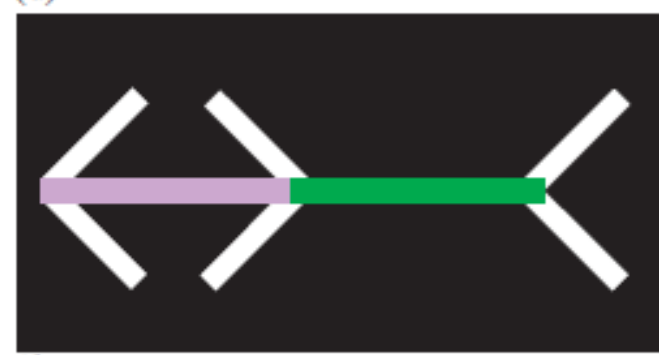

(f)

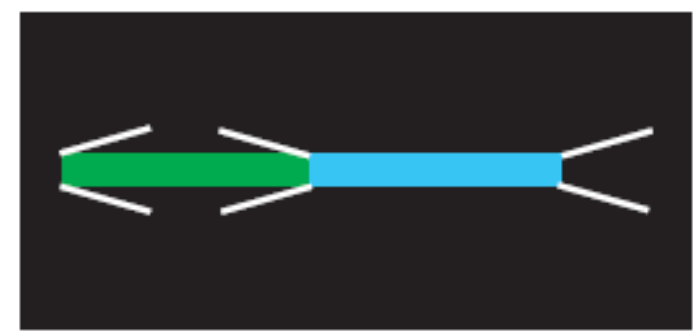

(h)

2.2.2 Brentano variation of Müller-Lyer figures. Alex was tested on the Brentano variation of the standard Müller-Lyer illusion (figure 3). This version, considered to be equivalent to the presentation of two separate figures (eg Sadza and de Weert 1984), ensured that he focused on both illusions 
simultaneously. Use of two central line colors and differently colored arrows allowed the experimenters to ask the parrot questions and receive its answers vocally, a reasonable trade for a small reduction such color differences might possibly cause in the strength of the illusion, if Alex responded as do humans. For humans, using differently colored arrowheads and shafts reduces the illusion by only 4\%-6\% [Miyahara 2006; Mukerji 1957; Sadza and de Weert 1984; note that Lamy et al (2006) found $\sim 10 \%$ reduction, but did not use solid figures]; using different central-line colors in the Brentano version might further decrease the illusion by only another 3\%-4\% according to Miyahara (2006), who suggests that a format that separates the two central lines facilitates accurate assessment of their length and thus a reduction of the illusion. Such a procedure allows replication of the form of the question while requiring a number of different answers (one of seven color labels or "none"'), which decreases the possibility of inadvertent cuing or training to a specific outcome. Interestingly, scientists initially suggested that using shafts and arrows of different colors would lead to more retinal blur and a larger illusion, but such is not the case, at least for humans (Coren et al 1978).

The initial Brentano figures were constructed so as to balance several concerns. Central lines were $10 \mathrm{~cm}$ long and $4 \mathrm{~mm}$ wide, half of one color and half of another, with black arrows $1 \mathrm{~mm}$ wide and $2.5 \mathrm{~cm}$ long emanating at $45^{\circ}$ angles from the horizontal. The $45^{\circ}$ angle and $1 \mathrm{~mm}$ width for the arrows were chosen as being both representative and intermediate in terms of processing of the illusion (eg Sekuler and Erlebacher 1971). The central lines were drawn so as to appear in front of the arrows, maximizing the illusion (Miyahara 2006). Sizes for the central lines and arrows were chosen so they could be clearly seen against the background and so that the arrows indeed appeared to emanate from the ends of the central lines. Stimuli were produced on a color laser printer (Panasonic KX-CL510), and Alex was tested with samples (single lines without arrows) prior to the introduction of the test stimuli to ensure that he would label the printed colors appropriately. Thus colors such as orange and purple--which can be problematic for Alex to identify (Pepperberg 1994, 2006) because parrots' abilities to see in the UV cause their color perception to differ somewhat from that of humans (Bowmaker et al 1994, 1996; Cuthill et al 2000; Goldsmith and Butler 2005; Wilkie et al 1998)--were adjusted appropriately.

Stimuli were, as in the familiarization trials, placed on a felt tray and held up vertically; Alex was asked either "What color bigger?" or "What color smaller?", in roughly equal proportions. Arguably, vertical placement might reduce the strength of the Müller-Lyer illusion (Heller 1992; Heller et al 2005) by reducing perceptual error and encouraging egocentric coding. During familiarization trials, however, Alex was far more likely to attend to vertical than horizontal stimuli, whatever the size differential of the lines. Thus the decision was made to retain the vertical presentation for the Müller-Lyer stimuli. Note that half of the time the stimulus was as shown in figure 3 and half of the time it was reversed so that the outward arrows were to the left to avoid any placement bias. Colors were mixed and matched, such that the purportedly correct response (that of seeing the illusion) was divided equally over the six colors he could label. We did, however, eliminate a few specific color combinations (orange with red or yellow, purple with red or blue) that Alex had in the past been likely to confuse because his color perception differed from that of humans (Pepperberg 1999).

2.2.3 White background tests with black arrows. These initial 6 trials, with stimuli depicted in figure 3a, were designed to determine if Alex was attending to both the arrows and the shafts. He labels the color black (as "grey") and thus could label all three elements of the figure, the two halves of the shaft and the arrows. When queried about 'smaller" (2 trials), he should respond with the color of the arrows--which were indeed the smallest item--rather than of a shaft. When queried about "bigger" (4 trials), he should label the half of the central shaft that he saw as longer. Thus, on trials with black arrows, his responses to "What color smaller?" were controls to determine if he could separate out the regions of interest--the shafts--from the arrows (a necessary behavior to ensure that he was not responding based on the 
distances including the arrows); his responses to "What color bigger?" were probes of the Müller-Lyer illusion.

2.2.4 Black background tests with white arrows. Interspersed with white background tests, and predominating later in the schedule, were 56 trials in which the stimuli were drawn on a black background with white arrows (figures 3b - 3h). Alex did not have the label 'white', and thus would be more likely to use the color of the central line to respond to "What color smaller?". For these stimuli, both queries (smaller, bigger) were probes of the illusion.

Ten stimuli were identical in form to those described above except for the reversal of background and arrow color (figure $3 b$ ); five additional types of stimuli, all on the black background, completed the series. As a control, on 3 trials the arrows were replaced by vertical bars perpendicular to the shafts (figure 3c) to determine, when the illusion definitely did not exist for human observers, whether Alex would respond "none" appropriately. Other stimuli were presented with central shaft widths that varied from the previous $4 \mathrm{~mm}$ : $6 \mathrm{~mm}$ width on 5 trials and $2 \mathrm{~mm}$ width on 11 trials (figures $3 \mathrm{~d}, 3 \mathrm{e}$ ). On these trials, the angle of the arrows remained at 458 and their width remained at $1 \mathrm{~mm}$. We also included 20 trials with equal shaft and arrow widths (4 mm for both--figure $3 \mathrm{f}$ ) as they are in standard tests with human observers. These variations tested whether emphasizing or de-emphasizing the shafts in contrast to the arrows would alter the effect of the illusion, as it does for humans (Coren and Porac 1983). Stimuli with thin shafts and arrows ( $2 \mathrm{~mm}$ and $1 \mathrm{~mm}$, respectively) and those with equal-width shafts and arrows (4 mm) should present the same illusion as the figures with medium shaft width and thin arrows $(4 \mathrm{~mm}$ and $1 \mathrm{~mm}$, respectively) but the illusion might fail with the thicker shafts and thin arrows $(6 \mathrm{~mm}$ and $1 \mathrm{~mm}$, respectively) if Alex responds as did Coren and Porac's human observers, for whom concentration on the shafts decreased the strength of the illusion.

The final two sets of figures involved angles at $10^{\circ}$ and $80^{\circ}$, again on black backgrounds. We included figures with $2 \mathrm{~mm}$ shafts with arrows approaching the vertical $\left(80^{\circ}\right.$--figure $\left.3 \mathrm{~g}\right)$ and $6 \mathrm{~mm}$ shafts with arrows approaching the horizontal $\left(10^{\circ}-\right.$--figure $\left.3 \mathrm{~h}\right)$ to determine if such perturbations shifted attention, respectively, to and from the shafts (Sekuler and Erlebacher 1971) and thus diminished or accentuated the effects of the illusion.

\subsection{Test procedure}

Initial testing, involving 32 trials, occurred on average 2 - 5 times per week from December 7, 2005 to June 7, 2006, with breaks for experimenter absences and scheduled dishabituation periods. Breaks of 1 3 weeks occurred after trials 16,18,21, 24, 29, 43, 47, 53, and 60 to determine if what appeared to be habituation to the illusion was indeed occurring, and whether absence of testing for a defined period would reinstate a response to the illusion. If no breaks, which often followed massed trials, are noted, 1 2 trials were given on sequential days. The second set of testing, involving another 32 trials, occurred with the same frequency from July 7, 2006 until September 14, 2006. Between these two sets was one trial with perpendicular arrows as an additional control (presented in both figures $4 \mathrm{a}$ and $4 \mathrm{~b}$ for continuity). Test questions were presented intermittently either during free periods (when Alex was requesting various foods or interactions) or during sessions on current (and thus unrelated) topics (eg testing Alex on number concepts).

Details of test procedures, including descriptions of precautions against inadvertent and expectation cuing are in Pepperberg $(1981,1994)$; summaries are below. A trial was generally repeated in a session only if Alex's initial answer was either a color that was not being presented or an indistinct response (eg Pepperberg 1981, 1987). Thus the number of times stimuli were presented to Alex depended on his behavior. Unless he produced a color not being presented or spoke indistinctly, he received praise and 
was allowed to request a reward. If his response was a nonexistent color label or indistinct, the examiner removed the tray, turned his/her head, and said "No!". Presentation continued until an appropriate identification was made or four attempts occurred; errors were recorded. If Alex consistently responded with nonexistent colors, the trial was dropped for noncompliance (see Pepperberg and Gordon 2005). When, approximately halfway through the first set of test trials, Alex began to respond "none" to every stimulus, for several trials (see below) he was asked, "Are you sure? What color bigger/smaller?" to ensure that he was not simply failing to attend; on such trials he was queried a total of four times.

As in all studies with Alex, the protocol differed from one used with other animals in two respects. First, the task capitalized on Alex's ability to work in the vocal mode; second, each trial was presented intermittently during training and testing of other unrelated topics also under study. Alex's responses thus had to be chosen from his entire repertoire (490 vocalizations, including labels for foods and locations) and from among numerous possible topics concerning various exemplars and questions during each session; that is, although the presence of the specific stimuli likely did cue Alex to the type of task being tested, he still had to attend to the specific type of question being posed. This design not only increased the complexity of the task, but prevented several forms of cuing (see below, also Pepperberg 1999; Premack 1976, page 132).

Test situations included specific precautions to avoid cuing. One control was a design such that each test session was, as noted above, presented intermittently during free periods or work on unrelated topics. An examiner who, for example, poses a series of similar questions may come to expect a particular answer and unconsciously accept an indistinct (and by our criteria incorrect) response of, for example, "gree" (a mix of "green" and "three") for "green". As noted above, Alex's responses had to be chosen from his entire repertoire and from among numerous possible topics during each session. Second, in general, a human other than the one presenting the tray (one of three possible individuals in these studies), who did not know what was on the tray, confirmed the answer; his/her interpretation of Alex's response was thus unlikely to be influenced by expectation of a certain label. Only after his/her confirmation was Alex rewarded (Pepperberg 1981). Third, this evaluator was unlikely to be influenced by hearing the type of question posed: in a previous study, transcriptions of contextless tapes of Alex's responses in a session agreed 98.2\% with original evaluations (Pepperberg 1992) ${ }^{4}$. Fourth, because Alex had not been trained on this task, no overlap occurred between training and testing situations and, because training on color labels had occurred years before, by students no longer present, he could not have picked up on trainerinduced cues specific to a given label (Pepperberg 1981).

Any direct cuing or training of Alex as to the correct answer by the presenter was highly unlikely for four reasons. First, in a previous two-item relative-size test in which the presenter was blind to the task (items were hidden in a cigar box) and the evaluator was out of Alex's view, Alex's accuracy of $78.7 \%$ (Pepperberg and Brezinsky 1991) was equivalent to his usual $\sim 80 \%$ rate (Pepperberg 1999); tests, however, took twice as long because of difficulty of maintaining Alex's attention to the task. Here, in four a-posteriori control trials in which the experimenter could not see the stimuli (figure $3 f$ versions, counterbalanced for question and arrow direction) and the evaluator was again out of Alex's view, the only effect was that trials took almost 15 min each because Alex could now use one of his eyes to focus on, and be distracted by, other events in the lab; he reported the illusion in the expected direction on three of the four trials, obviating the issue of cuing ${ }^{5}$. Second, unlike figure 1 , which is posed as noted, the stimulus was centered on one of Alex's eyes such that his head blocked most of the stimulus from the experimenter, and the experimenter's eyes were focused entirely on Alex's other eye and maintained that focus during questioning. Thus, the experimenter's eye gaze could not cue Alex as to which side (the 'bigger' or 'smaller') was correct in a given trial. Moreover, if he were indeed cuing into an experimenter's gaze to determine which color to label, he would not have made so many responses of "none" when the 
illusion was seen by the experimenter. Third, because the stimulus direction varied and questions varied between targeting bigger or smaller (ie questions were neither massed nor did not necessarily alternate, but could be either the same or different on a given day, and often only one question was asked on a given day), Alex could not learn to respond, for example, only to colors associated with arrows pointing in a particular direction, or to the right or left side. Also, because the specific response (one of six colors or 'none') varied from trial to trial, Alex could not be trained or cued as to one proper response, and the experimenter would praise him equally well no matter what he said (unless the response was, as noted above, irrelevant). Fourth, he was unlikely to have been trained or been cued as to the association between arrow direction and size, because his first actual error (giving a response in the incorrect direction) did not occur until trial 22.

Figure 4. Cumulative longitudinal graphs of Alex's reports for the Müller-Lyer figures. For each trial where Alex reported the illusion, the trace increases by one. When Alex reported no difference, the trace remains flat, and where he reported a difference in the direction opposite to the illusion, the trace drops. An overall rising trace indicates that Alex is systematically reporting the illusion. The record includes trials where an illusion is expected on the basis of human data (all blue and black square symbols, for example) and control trials where no illusion is expected (see text for details). The $W$ and $B$ in the key for the data symbols refer, respectively, to trials with white and black backgrounds; the trial values indicate the width of the central lines (shafts)--the arrows were always $1 \mathrm{~mm}$ in width. The degree notations refer to the angle of the arrow from the horizontal. The trace here represents the first set of trials, (a), from December 7, 2005 to June 7, 2006, and the continued trace, (b), the second set from July 7, 2006 to September 14, 2006. Trial 33 (a control version with perpendicular arrows) is on both charts for continuity.

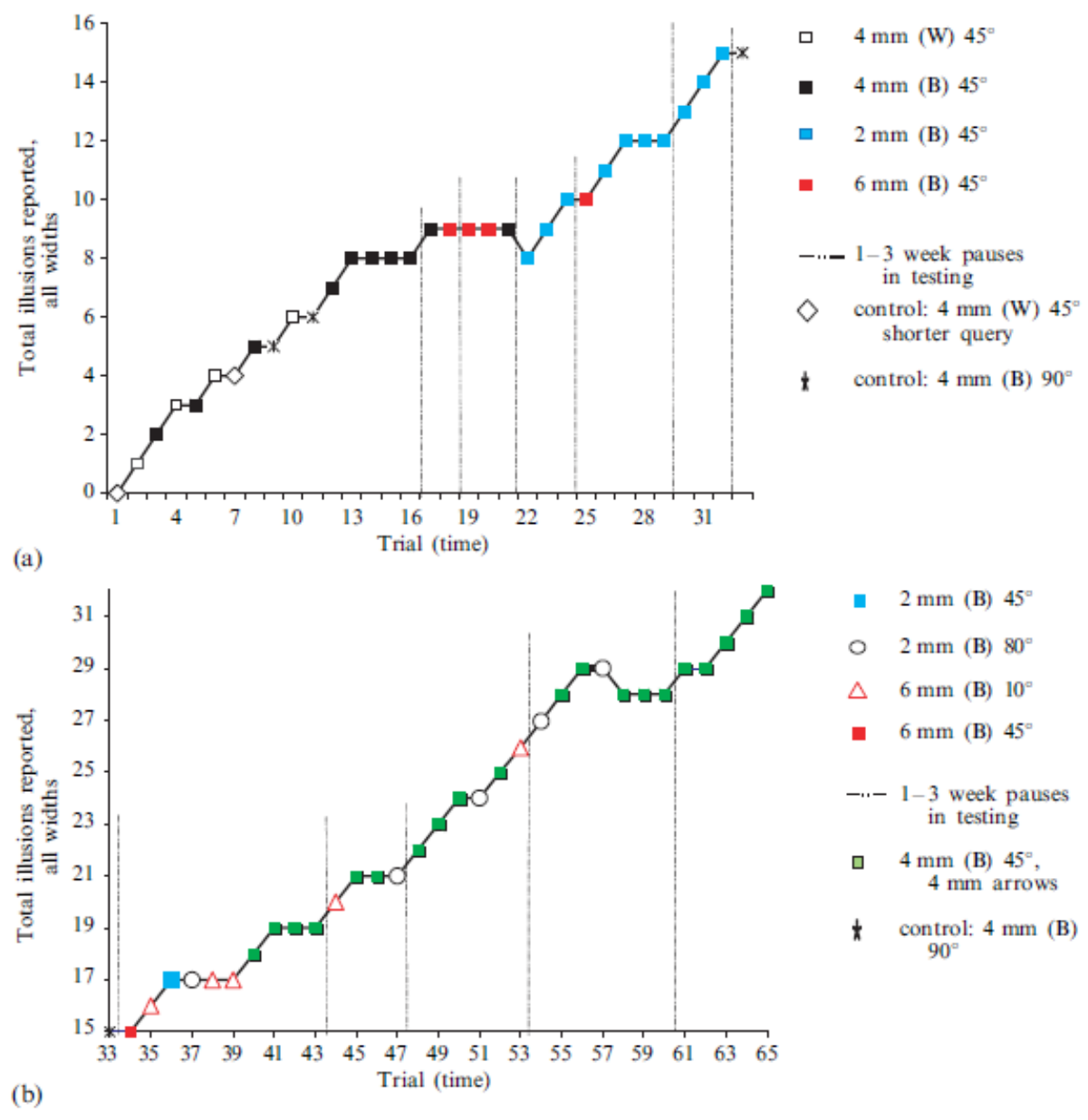


As in previous studies (eg Pepperberg 2006), a small percentage of sessions was videotaped and subsequently analyzed to ensure interobserver reliability. If interobserver reliability with a blind, naive coder was high, we could be assured of the validity of other trials. Given that Alex was more interested in the student performing the taping and the video camera rather than the objects to be labeled, such trials were difficult to execute and kept to a minimum. Four trials were digitized and presented to observers who had never interacted with Alex. One such trial is included as supplementary material.

\section{Results}

Alex's data were scored as 'illusion reported' if he named the color of the shaft that human observers would report, as 'no illusion' if he reported "none", and 'opposite the illusion' if he reported the color opposite to the illusion response. A cumulative trace of his responses across the various Müller-Lyer figures is shown in figures $4 \mathrm{a}$ and $4 \mathrm{~b}$. Percentages of reports in the illusion direction for standard and control versions are tabulated in figure 5 . The test procedure also allowed a question to be repeated (up to four times) until Alex named one of the two shaft colors or, in one control, the arrow color, or stated (and stuck with) "none". In general, Alex's first report was one of these appropriate responses. In about $10 \%$ of the trials, however, Alex initially stated colors that were not present but when queried a second time, gave one color that was present. Given that his accuracy in labeling colors is $80 \%-85 \%$ (errors occur either because of lack of attention to the stimuli or because stimuli that appear as one color to humans may appear as a different color to parrots--Pepperberg 1999), the second responses were used for these trials.

\subsection{Longitudinal responses}

Figures $4 \mathrm{a}$ and $4 \mathrm{~b}$ show Alex's trial-by-trial responses. He reported the illusion in about $65 \%$ of the trials where human observers would have shown the classic illusion (figure 5) and he showed a lessened or absent illusion in control trials where humans would not have shown the illusion. As shown in figure $4 a$, Alex initially reported the illusion with stimuli having $4 \mathrm{~mm}$ shafts and $1 \mathrm{~mm}$ arrows (black and white squares), then showed loss of the illusion after repeated trials, starting at trial 13. With the exception of the

5 control trials on which he was not expected to report the illusion (2 of these were trials with white background tests, diamonds on figure $4 \mathrm{a}$, where he was asked "What color smaller?" and where he could and did respond with the color of the arrows; 3 were figures with perpendicular arrows where no illusion is expected), he reported the illusion on 8 of his first 9 experimental trials (numbers 2, 3, 4, 6, 8, $10,12,13)$ with $4 \mathrm{~mm}$ shafts and $1 \mathrm{~mm}$ arrows. On the next 3 trials, however, he responded "none", possibly habituating to the illusion after repeated exposures (Mountjoy 1958). During further testing after a 2-week break, he again reported the illusion. As the trials continued, Alex showed continued illusion responses on the appropriate trials and the cumulative score rose steadily with only two reversals out of all 65 trials and only 18/50 null responses on trials where an illusion was expected, several of which may have been caused by habituation after repeated exposures.

\subsection{Effect of shaft and arrow width}

Shaft width systematically affected Alex's responses (figures $4 a, 4 b, 5$ ). He showed a consistent illusion response with the thinnest shafts ( $2 \mathrm{~mm}, 8 / 11$ illusion responses). Responses were again strongly in the illusion direction with the intermediate shaft width and arrows (4 mm shaft, $1 \mathrm{~mm}$ arrows, 9/14) and with the intermediate shaft and equal width arrows (both $4 \mathrm{~mm}, 12 / 20$ ). However, he never reported the illusion for $6 \mathrm{~mm}$ shafts and $1 \mathrm{~mm}$ arrows (0/5) even on trials after breaks from testing of 3 weeks (after trial 18) or 2 weeks (after trial 24). Alex does not appear to be responding to the overall lengths of the stimuli rather than to the illusion, as his responses varied from $0 \%$ to $73 \%$ for stimuli with exactly the same lengths but varying ratios of shaft/arrow widths. 
Figure 5. Percentage of stimuli for which Alex reported the Müller-Lyer illusion, broken down for shaft width, background color, controls, and arrow angles. W refers to trials on white backgrounds. 'Shorter query' refers to trials on white background, where Alex was asked "What color smaller?" and could answer the arrow color. With black backgrounds (B) the arrows were white, a color that Alex cannot name and so his answers, even for "What color shorter?", were limited to the two shaft colors. ' $\mathrm{mm}$ ' refers to the width of the central lines (shafts). The arrows were always $1 \mathrm{~mm}$ in width except for the one condition with $4 \mathrm{~mm}$ arrows (sixth from left). The degree notations refer to the angle of the arrow from the horizontal.

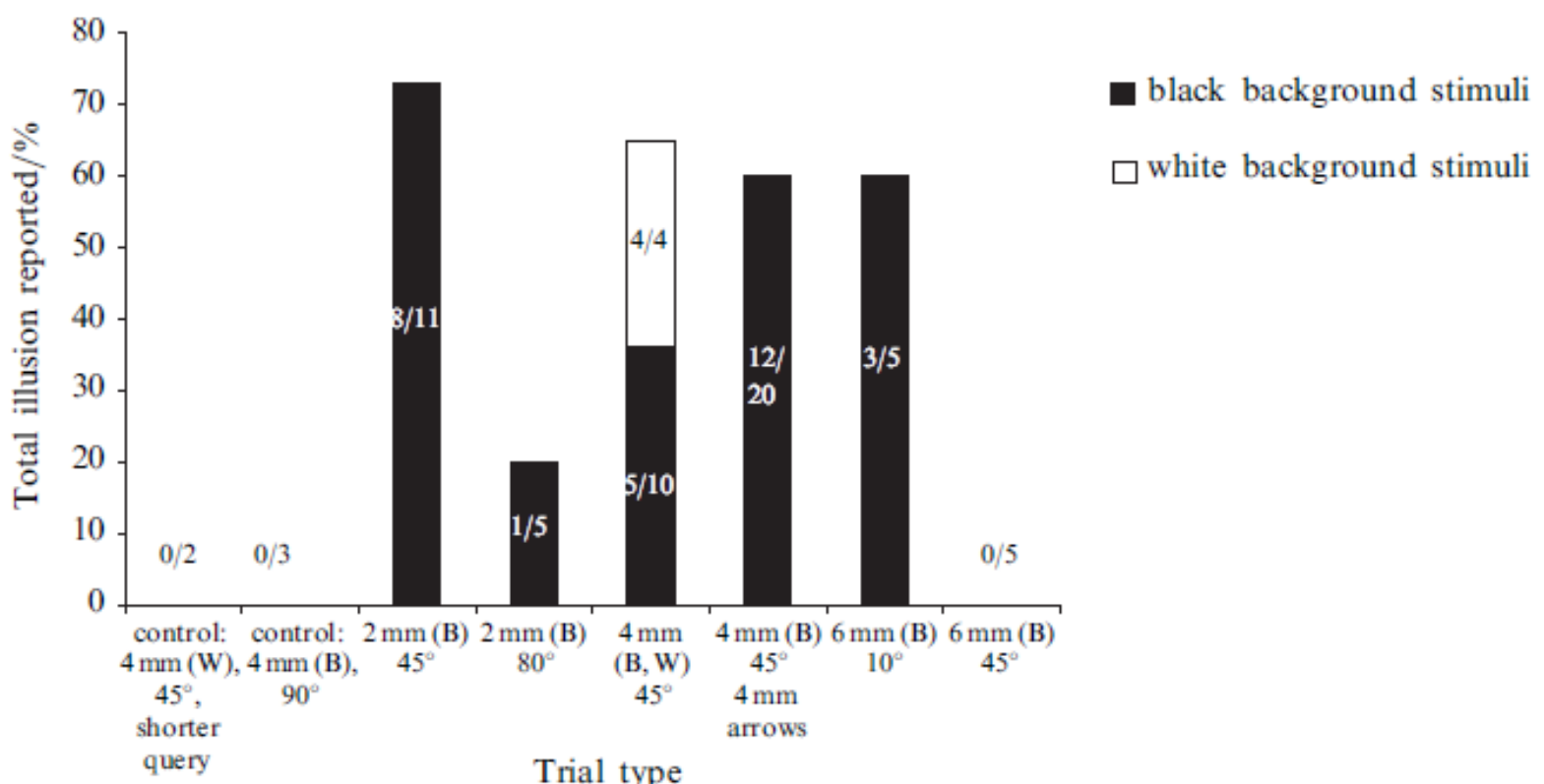

\subsection{Effect of shaft and arrow width}

Shaft width systematically affected Alex's responses (figures $4 a, 4 b, 5$ ). He showed a consistent illusion response with the thinnest shafts $(2 \mathrm{~mm}, 8 / 11$ illusion responses). Responses were again strongly in the illusion direction with the intermediate shaft width and arrows (4 mm shaft, $1 \mathrm{~mm}$ arrows, 9/14) and with the intermediate shaft and equal width arrows (both $4 \mathrm{~mm}, 12 / 20$ ). However, he never reported the illusion for $6 \mathrm{~mm}$ shafts and $1 \mathrm{~mm}$ arrows (0/5) even on trials after breaks from testing of 3 weeks (after trial 18) or 2 weeks (after trial 24). Alex does not appear to be responding to the overall lengths of the stimuli rather than to the illusion, as his responses varied from $0 \%$ to $73 \%$ for stimuli with exactly the same lengths but varying ratios of shaft/arrow widths.

\subsection{Effect of arrow angle}

The angles of the arrows had a strong effect, yielding a greater frequency of illusion reports for more acute angles and fewer or none for less acute angles. On the three trials with the arrow perpendicular to the shaft $(9,11$, and 33), Alex responded "none" as do human observers. When the arrow angle was set to $80^{\circ}$, approaching perpendicularity (figure $3 \mathrm{~g}$ ), he reported the illusion on only 1 of 5 trials. At the other extreme, when the arrows were set to $10^{\circ}$ (figure $3 \mathrm{~h}$ ), Alex reported the illusion on 3 of 5 trials even though the shaft width was $6 \mathrm{~mm}$, a width for which he did not report an illusion with the arrows at $45^{\circ}$ angles. 


\subsection{Habituation}

When trials were massed--more than one or two trials per day over several successive days--Alex often seemed to habituate, changing his illusion response to "none". This result can be seen at a number of points in the cumulative record (trials 13, 41 , and 57 for example). A break in testing typically restored the illusion responses.

\subsection{Responses to "What color smaller?" versus "What color bigger?"}

With the white-background stimuli, only 2 trials ( 1 and 7) were run in which Alex was asked "What color smaller?". In both, he responded "grey", the color of the arrows that were in fact the smallest elements in the test ('grey' is his label for items that range from grey through black). For the four tests with the white background when the question was "What color bigger?", Alex responded in the illusion direction on all 4 trials. With the black-background tests, the arrows were white, a color for which Alex had no label; he was thus likely to respond with a color for the shaft. For these tests, half the trials were "What color bigger?" and the other half "What color smaller?". No systematic difference existed in responses for these two types of trials for the black-background figures when illusion responses were expected $(63 \%$ and $65 \%$, respectively).

\subsection{Interobserver reliability}

4 trials were videotaped, digitized, and presented auditorially to four different observers (two female, two male) who were completely naive with respect to Alex's speech patterns; they could not see the stimuli Alex was being shown. All four agreed on their responses to all four samples. If we collapse all trials over all listeners, interobserver reliability is $100 \%$.

\subsection{Visual acuity}

Alex's acuity was tested with three sets of digits of different sizes $(6.3,12.7$, and $25.4 \mathrm{~mm}$ in height). The letters were arranged on a background at a viewing distance of 10 to $15 \mathrm{~cm}$ and Alex had to name the color of a probed digit ("What color 5?"). Performance was quite good (for the small number of trials) down to the smallest size tested. For the larger digits, Alex had 2 of 2 trials correct, for the $12.7 \mathrm{~mm}$ digits, 3 of 4 correct, and for the $6.3 \mathrm{~mm}$ digits, 4 of 5 correct. Because the Müller-Lyer figures were $10 \mathrm{~cm}$ or more in length, an order of magnitude larger than the small digits, there is little evidence that Alex would suffer any substantive blurring of the figure or even of the details where the central shaft met the arrows.

\section{Discussion}

Alex can, under a variety of conditions, perceive the Müller-Lyer illusion, thus demonstrating that neither human neuroanatomy and processing nor human binocular vision are required for such perception. Attention likely plays some role in the strength of the illusion as might visual experience. Our study also has implications for further comparative research.

\subsection{Effects of stimulus variation}

Alex's responses varied not with the overall length of the stimuli (arrows plus shaft) but with the ratio of the shaft/arrow width as well as the shaft/arrow angle. Had he responded solely to the total length of the stimuli (ie learned to respond to "What color bigger?" for outward arrows and to "What color smaller?" for inward arrows), he would not have failed to see the illusion in stimuli such as figure $3 \mathrm{~d}$ and would have seen the illusion more often than he did for stimuli based on figure 3f. Thus the data cannot be explained by a response to the overall length of the stimuli. 


\subsection{Comparative neurobiology, binocular vision}

Questions asking what brain areas are involved in processing the Müller-Lyer illusion and what areas might be functioning comparably in avian and human brains are still not fully answered. Data from a recent MRI study (Weidner and Fink 2007) suggest that the Müller-Lyer illusion in humans is processed in the lateral occipital cortex (LOC) and the right superior parietal cortex, with clear involvement of the right intraparietal sulcus (IPS). The LOC seems to process the line segments into the Müller-Lyer figure (note Tyler et al 2004); the posterior parietal cortex appears to integrate this information with 2-D depth cues and size-constancy scaling. Whether the human LOC relates to the lemnothalamic or collothalamic pathways--or a combination of both--in parrots is not known, but birds' visual areas function in a manner corresponding to the LOC (Butler et al 2005). Other studies have shown that human spatial attention and non-symbolic comparisons are also correlated to IPS activity (Coull and Nobre 1998; Fias et al 2003; Göbel et al 2001, 2004; Jordan et al 2004; Simon 1999) ${ }^{6}$; as noted previously (Pepperberg 2006), such abilities are essential for non-human survival (eg for predator detection; foraging comparisons) and nonhumans are thus likely to have analogous, if not homologous, brain areas. Although no MRI studies for the Müller-Lyer illusion have been performed on parrots, the avian nidopallium caudolaterale (NCL) and the dorsolateral corticoid (CDL) areas, which respectively are likely homologues of the posterior parietal cortex and parts of the prefrontal cortex (Butler et al 2005), would probably be involved in such processing.

Finally, Mountjoy (1960) demonstrated that, for humans, the Müller-Lyer illusion was less pronounced under monocular than binocular vision. Although we could not be sure that Alex was indeed viewing the illusion monocularly, it is possible that monocular vision might have contributed to his responses being less consistent than those that would have been found in human observers. As noted above, little is known about binocular overlap in Grey parrots, but it is purportedly somewhat less than 10\% (Walls 1942).

\subsection{Attention}

If humans attend to the shaft and ignore the arrows, the illusion is attenuated (see Gardner and Long 1961). Attentional effects may underlie some of the variability in response seen with Alex as well. Asking Alex about the colors of the shafts and making them six times the width of the arrows and changing the angle with respect to the shaft may have drawn his attention away from the arrows and reduced the illusion. He showed no length illusion in the perpendicular-arrow condition, a control to ensure that he was responding to the stimuli, nor to the $6 \mathrm{~mm}$-shaft condition, similar to the performance of human observers when the shaft is emphasized compared to the arrows (Coren and Porac 1983). He also showed a loss of the illusion after repeated trials, and a recovery following breaks in testing. Several researchers, from Mountjoy (1958) and Rudel and Teuber (1963) through Predebon (1998, 2006) have reported decrements of human perception of the Müller-Lyer illusion as a function of repeated exposure (see review in Millar and Al-Attar 2002); such an effect could have also occurred for Alex. Alex could, of course, simply have lost interest in the stimuli after repeated exposures, even though the exposures were not massed as densely as those in human studies. His lack of interest in a task is, however, generally expressed in either a total failure to respond or in a string of consistently incorrect responses (eg Pepperberg and Gordon 2005); nevertheless, he may have used "none" in such a manner in this study.

\subsection{Visual experience}

A separate but equally intriguing issue involves the effect of environmental stimuli on visual processing abilities. Specifically, humans living in what is often called a 'non-carpentered world'--ie an environment without significant examples of right-angled, parallel - perpendicular intersections--experience some 
optical illusions differently from humans in carpentered societies; in fact, some do not see the Müller-Lyer illusion at all (Segall et al 1966). Interestingly, in some non-carpentered societies children do see the Müller-Lyer illusions and adults do not whereas the opposite is true in other societies ${ }^{7}$, although few subjects of any age in non-carpentered societies see the illusion to the same extent as do Westerners (eg Segall et al 1966). Thus, for humans, the illusion is not likely innately specified but develops or degrades after interaction with the environment. One would expect wild parrots--likely lacking evolutionary pressures that would favor an adaptation for sensitivity to right-angled, parallel - perpendicular stimuli-to react as do humans in a non-carpentered society. Any captive-born parrot would, however, have the same experience as humans in carpentered societies, but would process these experiences with a nonprimate visual system. Demonstrating that even one captive Grey parrot responds to the Müller-Lyer illusion somewhat as do humans in carpentered societies strengthens the argument for the effects of visual input on the processing of the Müller-Lyer illusion (note McCauley and Henrich 2006), although comparisons with wild-caught parrots would be required for conclusive evidence.

\section{Conclusion}

At least one Grey parrot, Alex, reports the Müller-Lyer illusion under certain conditions. We recognize that our comparisons between parrots and humans, and even parrots and other avian species, are speculative, and are presented in order to generate further interest in cross-species comparisons. Our data suggest that this parrot would provide interesting information on other optical illusions and be an appropriate subject for other comparative studies of visual processing.

\section{Notes}

${ }^{1}$ An avian veterinarian, Dr Greg Harrison (personal communication, 4-14-06), also suggested that the parrot system was more like that of a chicken than a pigeon.

${ }^{2}$ Again, some of these studies involved memory rather than direct choice.

${ }^{3}$ Walls (1942) states that most parrots have a binocular overlap of $6 \%-10 \%$, but does not specify which species were studied. No data exist concerning the foveae of Grey parrots nor concerning their areas of highest visual acuity.

${ }^{4}$ This percentage represented 106 matches of 108 vocalizations. As an additional control, the principal investigator made two transcriptions of a student, new to the lab, as he responded to the same type of questions as Alex. The first transcription was live; the second, made several days later, was of a tape from which all questions had been edited. The two transcriptions of the student's vocalizations matched to within $95.8 \%$ (68 of 71 vocalizations).

${ }^{5}$ Fisher's exact test on Alex's results for figure $3 f$ trials during the experiment and after it show no significant differences ( $p=0: 514$, one-tailed).

${ }^{6}$ Coull and Nobre (1998) suggest that the left IPS is more active in temporal attention and the right IPS in spatial attention, but Fias et al (2003) find more activity in the left IPS for representation of symbolic and nonsymbolic magnitude. Cohen et al (2000) show that small bilateral intraparietal foci are more active in calculation abilities than in control tasks that also involve similar types of spatial or attentional abilities.

${ }^{7}$ Note work by Brosvic et al (2002) suggesting that 13 - 15 years seems to be the age at which Western children's decreasing sensitivity to the Müller-Lyer illusion reaches an asymptote. 


\section{Acknowledgments}

Research was supported by donors to The Alex Foundation, with special thanks to The Pearl Faüily Foundation, Alex and Michael Shulman, Greg LaMorte, William Lipton, Kathryn and Walter McAdams, Megumi Oka and the Makioka Foundation, Janice Boyd, Nancy Chambers, Mary Ogg, John Paton, Jan Hartley, Nancy Clark and Bill Broach, the Andrew De Mar Family Foundation, Noriko and Soshi Matsumoto, Hitomi Okumura, Jay Sugarman, Debby and Michael Smith, Janet and Kip Trumbule, Deborah Rivel and Robert Goodale, Mark Hagen, the Canadian Parrot Society, Mercedes Lackey, Mary Long, Ann Arbor Cage Bird Club, Great Lakes Avicultural Society, Kay Fewell, Deborah Thrasher, Tree Top Bird Center, Lisa Fortin Jackson, Paula Geheb, Jamie Whittaker, ABC Pets, 2luvbirds, Nancy Marbach, Georgia Hayes, Bird Paradise, Tracy Hylka/Bella Embroidery, Grey Feather Toy Creations, the Medwick Foundation, Featherlust Farms, Tammy Carreiro, Debbie Rijnders/Tinley Advies \& Producties BV, Vanessa Rolfe, LeighAnn and Carl Hartsfield, the Harrison family for Harrison's Bird Diet, Fowl Play, Gourmet Pet Supply, and Avian Naturals for treats, Carol D'Arezzo for Alex's perch, and Avian Adventures for cages and additional financial support.

\section{References}

Aust J, Huber L, 2006 "Does the use of natural stimuli facilitate amodal completion in pigeons?" Perception 35333 - 349

Bowmaker J K, Heath L A, Das D, Hunt D M, 1994 "Spectral sensitivity and opsin structure of avian rod and cone visual pigments" Investigative Ophthalmology and Visual Science 351708

Bowmaker J K, Heath L A, Wilkie S E, Das D, Hunt D M, 1996 "Middle-wave cone and rod visual pigments in birds: Spectral sensitivity and opsin structure" Investigative Ophthalmology and Visual Science 37 S804

Brosvic G M, Dihoff R E, Fama J, 2002 "Age-related susceptibility to the Müller-Lyer and the Horizontal Vertical illusions" Perceptual and Motor Skills 94229 - 234

Butler A B, Manger P R, Lindahl B I B, Århem P, 2005 "Evolution of the neural basis of consciousness: A bird - mammal comparison" BioEssays 27923 - 936

Changizi M A, Widders D M, 2002 "Latency correction explains the classical geometric illusions" Perception 311241 - 1262

Cohen L, Dehaene S, Cochon F, Lehéricy S, Naccache L, 2000 "Language and calculation within the parietal lobe: a combined cognitive, anatomical, and fMRI study" Neuropsychologia 381426 1440

Cook R G, 2001 Avian Visual Cognition [online: www.pigeon.tufts.edu/avc]

Cook R G, Goto K, Brooks D I, 2005 "Avian detection and identification of perceptual organization in random noise" Behavioural Processes 6979 - 95

Coren S, Porac C, 1983 "The creation and reversal of the Müller-Lyer illusion through attentional modulation" Perception $1249-54$

Coren S, Ward L M, Porac C, Fraser R, 1978 "The effect of optical blur on visual-geometric illusions" Bulletin of the Psychonomic Society 11390 - 392

Coull J T, Nobre A, 1998 "Where and when to pay attention: the neural systems for directing attention to spatial locations and to time intervals as revealed by both PET and fMRI" Journal of Neuroscience 187426 - 7435

Cuthill I C, Hart N S, Partridge J C, Bennett A T D, Hunt S, Church S C, 2000 "Avian color vision and avian color playback experiments" Acta Ethologica 329 - 37

DiPietro N T, Wasserman E A, Young M E, 2002 "Effects of occlusion on pigeons' visual object recognition" Perception 311299 - 1312

Dücker G, 1966 "Optical illusions in vertebrates" Zeitschrift für Tierpsychologie 24452 - 496 
Emery N J, Clayton N S, 2004 "The mentality of crows: convergent evolution of intelligence in corvids and apes" Science 3061903 - 1907

Fias W, Lammertyn J, Reynvoet B, Dupont P, Orban G A, 2003 "Parietal representation of symbolic and nonsymbolic magnitude" Journal of Cognitive Neuroscience 1547 - 57

Frost B J, Wise L Z, Morgan B, Bird D, 1990 "Retinotopic representation of the bifoveate eye of the kestrel (Falco sparverius) on the optic tectum" Visual Neuroscience 5231 - 239

Fujita K, Blough D S, Blough P M, 1993 "Effects of the inclination of context lines on perception of the Ponzo illusion by pigeons" Animal Learning \& Behavior 2129 - 34

Gardner R W, Long R I, 1961 "Selective attention and the Müller-Lyer illusion" Psychological Record 11 $317-320$

Göbel S, Walsh V, Rushworth M F S, 2001 "The mental number line and the human angular gyrus" Neurolmage 141278 - 1289

Göbel S M, Johansen-Berg H, Behrens T, Rushworth M F S, 2004 "Response-selection-related parietal activation during number comparison" Journal of Cognitive Neuroscience 161536 - 1551

Goldsmith T, Butler B K, 2005 "Color vision of the budgerigar (Melopsittacus undulatus): hue matches, tetrachromacy, and intensity discrimination" Journal of Comparative Physiology A, Neuroethology, Sensory, Neural, and Behavioral Physiology 191933 - 951

Gregory R L, 1968 "Perceptual illusions and brain models" Proceedings of the Royal Society of London, Series B 171279 - 296

Heller M A, 1992 "The effect of orientation on tactual braille recognition: Optimal 'touching positions'”' Perception \& Psychophysics 51549 - 556

Heller M A, McCarthy M, Schultz J, Greene J, Shanley M, Clark A, Skoxzylas S, Prociuk J, 2005 "The influence of exploration mode, orientation, and configuration on the hepatic Müller-Lyer illusion" Perception 341475 - 1500

Jarvis E D, Güntürkün O, Bruce L, Csillag A, Karten H, Kuenzel W, Medina L, et al (there are 22 further authors), 2005 "Avian brains and a new understanding of vertebrate evolution" Nature Reviews Neuroscience 6151 - 159

Jordan K, Schadow J, Wuestenberg T, Jeinze H-J, Jäncke L, 2004 "Different cortical activations for subjects using allocentric or egocentric strategies in a virtual navigation task" Brain Imaging 15 $135-140$

Lamy D, Segal H, Ruderman L, 2006 "Grouping does not require attention" Perception \& Psychophysics $6817-31$

McCauley R N, Henrich J, 2006 "Susceptibility to the Müller-Lyer illusion, theory-neutral observation, and the diachronic penetrability of the visual system" Philosophical Psychology $1979-101$

Miller S, Al-Attar Z, 2002 "The Müller-Lyer illusion in touch and vision: Implications for multisensory processes"' Perception \& Psychophysics 64353 - 365

Miyahara E, 2006 "Effects of chromaticities and occlusion of shaft on magnitude of the Müller-Lyer illusion" Perceptual and Motor Skills 102259 - 264

Mountjoy P T, 1958 "Effects of exposure time and intertrial interval upon decrement to the Müller-Lyer illusion" Journal of Experimental Psychology 5697 - 102

Mountjoy P T, 1960 "Monocular regard and decrement to the Müller-Lyer illusion" Psychological Record $10141-143$

Mukerji N, 1957 “Is 'illusion' illusion?" Journal of General Psychology 57209 - 212

Müller-Lyer F C, 1889/1981 "Optische Urtheilstäuschungen" Archiv für Anatomie und Physiologie, Physiologische Abteilung 2 (Supplement) 263 - 270, Translation by R H Day, H Knuth, 1981 "'The contributions of F.C. Müller-Lyer" Perception 10126 - 146

Nakamura N N, Fujita K F, Ushitani T U, Miyata H M, 2005 "Perception of the Müller-Lyer illusion in pigeons and humans", paper presented at the International Ethological Congress, Budapest, August 
Nakamura N, Fujita K, Ushitani T, Miyatat H, 2006 "Perception of the standard and the reversed MüllerLyer figures in pigeons (Columba livia) and humans (Homo sapiens)" Journal of Comparative Psychology 120252 - 261

Nguyen A P, Spetch ML, Crowder N A, Winship I R, Hurd P L, Wylie D RW, 2004 "A dissociation of motion and spatial-pattern vision in the avian telencephalon: implications for the evolution of 'visual streams' " Journal of Neuroscience 244962 - 4970

Otto-deHaart G, Carey D P, Milne A B, 1999 "More thoughts on perceiving and grasping the Müller-Lyer illusion" Neuropsychologia 371437 - 1444

Pepperberg I M, 1981 "Functional vocalizations by an African Grey parrot (Psittacus erithacus)" Zeitschrift für Tierpsychologie 55139 - 160

Pepperberg I M, 1987 "Acquisition of the same/different concept by an African Grey parrot (Psittacus erithacus): Learning with respect to categories of color, shape, and material" Animal Learning \& Behavior 15423 - 432

Pepperberg I M, 1992 "Proficient performance of a conjunctive, recursive task by an African Grey parrot (Psittacus erithacus)" Journal of Comparative Psychology 106295 - 305

Pepperberg I M, 1994 "Evidence for numerical competence in an African Grey parrot (Psittacus erithacus)" Journal of Comparative Psychology 10836 - 44

Pepperberg I M, 1999 The Alex Studies: Cognitive and Communicative Abilities of Grey Parrots (Cambridge, MA: Harvard University Press)

Pepperberg I M, 2006 "Addition by a Grey Parrot (Psittacus erithacus), including absence of quantity" Journal of Comparative Psychology 1201 - 11

Pepperberg I M, Brezinsky M V, 1991 "Acquisition of a relative class concept by an African Grey Parrot (Psittacus erithacus): Discriminations based on relative size" Journal of Comparative Psychology $105286-294$

Pepperberg I M, Gordon J, 2005 "Numerical comprehension by a Grey Parrot (Psittacus erithacus), including a zero-like concept" Journal of Comparative Psychology 119197 - 209

Pepperberg I M, Wilkes S R, 2004 "Lack of referential vocal learning from LCD video by Grey parrots (Psittacus erithacus)" Interaction Studies 575 - 97

Premack D, 1976 Intelligence in Ape and Man (Hillsdale, NJ: Lawrence Erlbaum Associates)

Predebon J, 1998 "Decrement of the Brentano Müller-Lyer illusion as a function of inspection time" Perception 27183 - 192

Predebon J, 2004 "Selective attention and asymmetry in the Müller-Lyer illusion" Psychonomic Bulletin Review 11916 - 920

Predebon J, 2006 "Decrement of the Müller-Lyer and Poggendorff illusions: the effects of inspection and practices" Psychological Research 70384 - 394

Regolin L, Marconato F, Vallortigara G, 2004 "Hemispheric differences in the recognition of partly occluded objects by newly hatched domestic chicks (Gallus gallus)" Animal Cognition 7162 - 170

Rudel R G, Teuber H-L, 1963 "Decrement of visual and haptic Müller-Lyer illusion on repeated trials: A study of crossmodal transfer" Quarterly Journal of Experimental Psychology 15125 - 131

Sadza K J, de Weert C M M, 1984 "Influence of color and luminance on the Müller-Lyer illusion" Perception \& Psychophysics $35214-220$

Segall M, Campbell D, Herskovitz M J, 1966 The Influence of Culture on Visual Perception (New York: Bobs-Merrill)

Sekuler R, Erlebacher A, 1971 "The two illusions of Müller-Lyer: Confusion theory reexamined" American Journal of Psychology 84477 - 486

Simon T J, 1999 "The foundations of numerical thinking in a brain without numbers" Trends in Cognitive Sciences 3363 - 365

Turnbull O H, Driver J, McCarthy R A, 2004 "2D but not 3D: Pictorial deficits in a case of visual agnosia" Cortex $40723-738$ 
Tyler C W, Likova L T, Wade A R, 2004 "Properties of object processing in lateral occipital cortex" [Abstract] Journal of Vision 4 91a

Vallar G, Daini R, Antonucci G, 2000 "Processing of an illusion of length in spatial hemineglect: a study of bisection" Neuropsychologia 381087 - 1097

van Hamme L J, Wasserman E A, Biederman I, 1992 "Discrimination of contour-deleted images by pigeons" Journal of Experimental Psychology: Animal Behavior Processes 18387 - 399

Walls G L, 1942 The Vertebrate Eye and Its Adaptive Radiation (Bloomfield Hills, MI: Cranbrook Institute of Science) page 295

Warden D J, Baar J, 1929 "The Müller-Lyer illusion in the ring dove, Turtur risorius" Journal of Comparative Psychology 9275 - 292

Weidner R, Fink G R, 2007 "The neural mechanisms underlying the Müller-Lyer illusion and its interaction with visuospatial judgments" Cerebral Cortex $17878-884$

Wilkie S E, Vissers P M A M, Das D, DeGrip W J, Bowmaker J K, Hunt D M, 1998 "The molecular basis for UV vision in birds: spectral characteristics, cDNA sequence and retinal localization of the UVsensitive visual pigment of the budgerigar (Melopsittacus undulatus)" Biochemical Journal 330 $541-547$

Winslow C N, 1933 "Visual illusions in the chick" Archives of Psychology 1531 - 83

Zanker J M, Abdullah A K, 2004 "Are size illusions in simple line drawings affected by shading" Perception 331475 - 1482 